Cita bibliográfica: Martín Delgado, L. M., Rengifo Gallego, J. I. y Sánchez Martín, J. M. (2019). El turista cinegético. Una aproximación a su perfil en la comunidad autónoma de Extremadura. Investigaciones Turísticas (18), pp. 193-219. http://dx.doi.org/10.14198/INTURI2019.18.09

\title{
El turista cinegético. Una aproximación a su perfil en la comunidad autónoma de Extremadura
}

\author{
Hunting tourists. An approach to their standard profile in Extremadura
}

Luz María Martín Delgado (iD, Universidad de Extremadura, España luzmariamd@unex.es

Juan Ignacio Rengifo Gallego iD, Universidad de Extremadura, España irengifo@unex.es

José Manuel Sánchez Martín (iD, Universidad de Extremadura, España imsanche@unex.es

\section{RESUMEN}

El turismo es un sector económico que ha alcanzado en el siglo XXI un notorio auge, tanto a nivel nacional como internacional, de acuerdo con los datos que ofrecen diferentes fuentes. Dentro de este sector existen numerosas modalidades de carácter específico, siendo una de ellas el turismo cinegético. En este trabajo se aborda una de las cuestiones menos conocida de esta tipología turística: el perfil de la demanda. Para ello se ha recurrido al uso de fuentes primarias recopiladas por el Observatorio Turístico de Extremadura, vía encuesta, en las oficinas de turismo de la comunidad autónoma. Los resultados han sido tratados mediante la aplicación de técnicas estadísticas descriptivas. De este análisis se han obtenido importantes resultados que han permitido generar conocimiento sobre las características del perfil de la demanda. Entre los resultados obtenidos cabe destacar la singular caracterización sociodemográfica, las peculiares características del viaje realizado y el indudable interés que tienen estos turistas por el desarrollo de otras actividades distintas a las de la práctica de las artes venatorias.

Palabras clave: Caza, turismo cinegético, perfil de la demanda, caracterización, Extremadura.

\section{ABSTRACT}

Tourism, as an economic sector, has expanded exponentially in the twenty-first century-both in Spain and on a global scale-according to data from different sources. There are a number of highly-specific kinds of tourism, one of which is the so-called 'hunting tourism'. This study addresses one of the most neglected aspects of this type of tourism: the profile of the average 
tourist. In order to determine this profile, this article draws from primary data compiled by the Extremadura Observatory for Tourism, by means of a survey conducted at the Tourist Offices of the region. The relevant data have been analyzed using descriptive statistical methods. This analysis has yielded important results that have been used to characterize the profile of the hunting tourist. Among the most significant characteristics, the following should be noted: socio-demographic characteristics; travel patterns and practices; and the interest these tourists show for activities other than hunting.

Keywords: Hunting, Hunting Tourism, Tourist Profile, Characterization, Extremadura

\section{INTRODUCCIÓN}

El turismo es un fenómeno del que se derivan importantes beneficios, así como costes de diferente orden, que ha adquirido una enorme repercusión mundial durante el siglo XXI en sus facetas de actividad económica y social. A esta situación se ha llegado tras un proceso de crecimiento que alcanzó una especial dimensión en la segunda mitad del siglo XX, momento en el que diferentes factores propiciaron el desarrollo exponencial del turismo $y$, como resultado de ello, de la aparición del denominado turismo de masas. Las estadísticas actuales corroboran la magnitud que ha alcanzado este pujante sector económico, hasta el punto de convertirse en uno de los adalides del actual proceso de internacionalización. Las llegadas de turistas internacionales registraron un notable aumento de casi el 7\% en el año 2017 hasta alcanzar un total de 1.323 millones (OMT, 2018). A su vez, las previsiones apuntan a que este fuerte impulso se mantendrá en 2018 con un ritmo de crecimiento de entre el $4 \%$ y el 5\%, lo que significará que el turismo internacional viene creciendo de forma sostenida, aunque a ritmos diferentes, desde que existen cifras al respecto.

Profundizando en esta cuestión, hay que señalar que estas cifras, a pesar de su tamaño, no son más que una parte significativa de lo que realmente genera esta actividad, ya que a ellas habría que incorporar los movimientos turísticos, sin salir de sus fronteras, de las personas residentes en un país determinado. Como prueba de esta aseveración se podría citar el número de viajes turísticos de los residentes españoles dentro de España, que durante el año 2017 alcanzó el considerable monto de 176 millones de los que se derivaron 660 millones de pernoctaciones (INE, 2017). A la vista de estos datos se puede afirmar que el turismo es una fuente de la que fluyen importantes ingresos que crean empleo y contribuyen al desarrollo económico de un buen número de ciudades, regiones o países, según el caso.

Este significativo número de personas que compone la demanda se desplaza en virtud de una gran diversidad de motivaciones que ha dado lugar a la aparición de diferentes tipologías turísticas que pueden clasificarse en dos grandes bloques: turismos genéricos y turismos específicos (Torres, 2006). A su vez, la aparición de nuevas motivaciones muestra un enorme dinamismo por dos razones fundamentales: el insaciable deseo de conocer y/o experimentar que tiene una demanda cada vez más informada y el papel que juegan los agentes públicos y privados del sector turístico que se ven obligados a competir bajo el marco de la constante necesidad de ofertar algo nuevo y, por ende, de la innovación. Esta es la razón por la que cuesta estar al día sobre la relación de modalidades o tipologías turísticas específicas que, 
desde la óptica de la demanda, surgen cada temporada y son bautizadas con nombres, en ocasiones, muy mediáticos y comerciales.

Algunas de las tipologías de turismos específicos cuentan con una trayectoria muy breve, mientras que hay otras que poseen un recorrido mucho más dilatado, sin que esta circunstancia se pueda relacionar con el tamaño actual de la demanda de cada una de ellas. En el caso concreto de este artículo se abordan diferentes aspectos relacionados con el perfil de la demanda de un turismo específico que cuenta con cierta trayectoria: el turismo de caza o turismo cinegético. Se trata de un turismo que, desde el punto de vista conceptual, fue definido por Rengifo (2008, p. 190), "como aquel que engloba el conjunto de actividades llevadas a cabo por las personas que se desplazan a un espacio concreto, atraídas por el recurso caza, con el objeto de capturar con criterios sostenibles una pieza, utilizando distintas técnicas y medios. A su vez, el recurso caza está constituido por determinadas especies de animales, divididas en especies de caza mayor y menor, cuya distribución por el territorio, en términos de variedad y densidad, presenta realidades asimétricas". Esta modalidad turística se inserta, para algunos autores, dentro de áreas temáticas más extensas como la del turismo deportivo (Torres, 2006) o el turismo de naturaleza (Petroman et al., 2015). La actividad cinegética, en su faceta deportiva, se muestra como una de las que acumula un mayor número de licencias federadas, sólo superada por el fútbol y el baloncesto, según lo expuesto en las últimas cifras publicadas por la División de Estadística y Estudios de la Secretaría General Técnica del Ministerio (2017), al registrar en el año 2017 un total de 328677 licencias de caza federadas en España.

Esta modalidad turística tiene sus orígenes en el siglo XIX, periodo en el que se han podido constatar desplazamientos hacia destinos de caza, tanto a escalas intra, como supranacionales. Bauer y Giles (2002) citan como ejemplos clásicos de destinos internacionales, durante el siglo XIX, los casos de África y Asia. A pesar de ello el corpus bibliográfico sobre la materia es escaso, aun teniendo en cuenta las múltiples ópticas bajo las que puede ser tratada esta tipología turística: histórica, económica, geográfica, ecológica o sociológica, por citar algunos ejemplos de entre las más relevantes. En el caso de la Geografía, y ciñéndose al ámbito nacional, Adrover, Grimalt y Binimelis (2017), en un exhaustivo trabajo sobre los estudios geográficos de la caza en España en el periodo 1978-2015, citan 13 obras que abordan esta materia. Esta cifra se antoja escasa, teniendo en cuenta, además, que estos trabajos no acometen en todos los casos la cuestión de forma monográfica, sino que en ocasiones lo hacen de modo tangencial.

De forma sintética se puede expresar que los enfoques de los trabajos específicos sobre turismo cinegético a nivel nacional se pueden agrupar en dos bloques:

- En primer lugar, se observa la existencia de trabajos que han sido abordados bajo un enfoque centrado en la oferta, con el propósito de describir la existencia de una materia prima que se disocia entre los espacios de caza (tipologías y extensión de los terrenos apropiados para cazar) y la diversidad de especies cinegéticas (variedad y cantidad en caza mayor y menor). En la mayor parte de estos casos el discurso se ha centrado en enfatizar, de forma descriptivo-interpretativa, en las posibilidades que ofrece un territorio concreto para atraer cazadores con la finalidad de aprovechar el recurso caza (Borrell, 1964) y, como consecuencia de ello, generar actividad económica en zonas 
con escasas posibilidades de desarrollo. Estos análisis han tenido una visión nacional (Mulero, 1991; Rengifo, 2009) o regional (Rengifo, 2010, 2012, 2016).

- Más recientemente han sido publicados algunos trabajos centrados en la demanda, gracias a la obtención de datos directos de los cazadores, a través de encuestas, o bien a través de análisis vinculados a los datos que contienen las licencias de caza (lugar de residencia del cazador). Con ellos se ha tratado de definir el perfil del cazador, tarea que genera conocimiento y se convierte en una herramienta útil de cara a la redacción de estrategias por parte de agentes públicos y privados interesados en la cuestión. En líneas generales se trata de trabajos con un carácter muy local: Extremadura y Castilla La Mancha (Rengifo, 2011), provincia de Córdoba (Nogueras, Caridad y Gálvez, 2017) o isla de Mallorca (Adrover, Grimalt y Binimelis, 2017).

A estas referencias bibliográficas de ámbito nacional habría que incorporar otras de carácter internacional en las que se ha tratado la cuestión en base a análisis globales, locales, genéricos y específicos bajo múltiples matices (Leader William, Kayera y Overtoil, 1996; Bauer y Giles, 2002; Mbaiwa, 2004; Lindsey, Roulet y Romañach, 2007; Samuelson y Stage, 2007; Willebrand, 2009; Komppula y Gartner, 2013; Krüger, Barrat y Van der Merwe,2015; Petroman, Petroman y Marin 2015).

Bajo estas premisas, el objetivo principal de este artículo es el de generar conocimiento sobre una faceta del turismo cinegético escasamente estudiada desde el ámbito académico: el perfil de la demanda. Complementariamente se han establecido una serie de objetivos secundarios entre los que se encuentra establecer el perfil sociodemográfico del turista cinegético en esta región, conocer las características que definen su viaje, estimar su movilidad y, por último, identificar la opinión de estos turistas sobre Extremadura como destino de turismo cinegético. Para conseguir esta amplia gama de propósitos ha sido necesario recurrir a fuentes primarias, conformadas por encuestas recopiladas en las oficinas de turismo de Extremadura, tal y como se explica con detalle en el punto II de este artículo.

El artículo se estructura en los siguientes epígrafes:

- Introducción. En este primer bloque se acomete una contextualización del fenómeno y se repasa el nivel de conocimiento de esta modalidad turística escasamente estudiada, tanto dentro como fuera de Extremadura, especialmente en los aspectos relacionados con la demanda.

- Metodología. En él se describen las fuentes y técnicas empleadas para el desarrollo de la presente investigación.

- Situación de la caza en Extremadura. En este apartado se aborda una breve síntesis de la situación actual de la caza en Extremadura, utilizando para ello diferentes fuentes de información secundarias: Junta de Extremadura, Fundación Artemisan y Federación Extremeña de Caza.

- En el punto cuarto se describe el fenómeno del turismo cinegético en Extremadura.

- Por último, antes de extraer las conclusiones, se exponen los resultados obtenidos tras el pertinente análisis de los datos procedentes de las fuentes primarias. 


\section{METODOLOGÍA}

Con objeto de alcanzar los objetivos planteados en esta investigación se ha recurrido a dos fuentes de información: el Observatorio de Turismo de Extremadura y el Instituto Geográfico Nacional. Del primero de los casos procede la información alfanumérica, que ha aportado los datos generados de una encuesta cumplimentada por los turistas que pasaron por las distintas oficinas de turismo localizadas por todo el territorio extremeño durante el año 2017. Si bien, dado el matiz de este estudio, se han delimitado aquéllas que tenían como motivación la caza. La encuesta es una técnica ampliamente utilizada para la caracterización del perfil del turista de diversas modalidades (Sastre, 2004; Arizón, Garcés y Sangrá, 2012; Folgado-Fernández, Hernández-Mogollón y Duarte, 2014).

Las preguntas formuladas, representadas en la Tabla 1, permiten un análisis aproximativo del perfil del turista cinegético en cuatro aspectos significativos: el sociodemográfico, la caracterización del viaje, la movilidad interna y la percepción del destino.

Esta fuente se ha complementado con la base cartográfica numérica (BCN100) a escala 1:100 000 procedente del Instituto Geográfico Nacional con el fin de implementar la información previa en un Sistema de Información Geográfica, lo que ha permitido la elaboración de cartografía temática.

Tabla 1. Preguntas de la encuesta 2017

\begin{tabular}{|c|c|}
\hline 1. Sexo & \\
\hline 2. Lugar de Residencia habitual & $\begin{array}{l}\text { Lugar de residencia habitual de españoles } \\
\text { Lugar de residencia habitual de extranjeros }\end{array}$ \\
\hline 3. Edad & \\
\hline 4. Con quién viaja & \\
\hline 5. Medio de organización del viaje & \\
\hline 6. Pernocta & $\begin{array}{l}\text { Cuántas noches } \\
\text { Dónde pernocta }\end{array}$ \\
\hline 7. Qué tipo de alojamiento utiliza & \\
\hline 8. Qué tipo de actividad va a realizar & \\
\hline 9. Qué zonas tiene pensado visitar & $\begin{array}{l}\text { 9.1. Localidades } \\
\text { 9.2. Espacios naturales }\end{array}$ \\
\hline 10. Gasto diario por persona & $\begin{array}{l}\text { 10.1. Alojamiento } \\
\text { 10.2. Alimentación } \\
\text { 10.3. Otras compras }\end{array}$ \\
\hline 11. Valoraciones & $\begin{array}{l}\text { 11.1. Acogida y hospitalidad } \\
\text { 11.2. Oferta de alojamiento } \\
\text { 11.3. Oferta de restauración } \\
\text { 11.4. Oferta de empresas de actividades turísticas } \\
\text { 11.5. Profesionalidad del sector } \\
\text { 11.6. Accesibilidad para discapacitados } \\
\text { 11.7. Servicio de Información turística en destino } \\
\text { 11.8. Señalización turística } \\
\text { 11.9. Facilidad para llegar y desplazarse } \\
\text { 11.10. Conservación del Patrimonio Cultural } \\
\text { 11.11. Conservación del Patrimonio Natural }\end{array}$ \\
\hline
\end{tabular}

Fuente: Observatorio de Turismo Extremadura 
El volumen de encuestas realizadas para analizar el perfil del turista cinegético que visita Extremadura es reducido si se considera un universo de 40 887, correspondiente a las licencias de cazadores expedidas en Extremadura durante 2017, pues se carece de información más precisa sobre el número de turistas de esta tipología en la región. Pese a ello, si se acepta que el propio valor de universo es el máximo posible de cazadores, no solo turistas cinegéticos, para un nivel de confianza del $95 \%$, se obtiene un error muestral del $10,8 \%$ en el peor de los casos y un 6,5\% para el caso más favorable.

Estos valores muestrales permiten obtener una aproximación al perfil del turista cinegético, con un grado de exactitud aceptable si se parte de las propias limitaciones que impone la determinación del universo estadístico y el número de encuestas válidas utilizadas. Para solventar estas limitaciones que nos surgen de la carencia de una muestra de mayor tamaño, se tendrán en cuenta los datos obtenidos en otra encuesta que ha sido cumplimentada por las Sociedades Locales de Cazadores federadas en Extremadura mediante formularios de Google Drive y en la que se han obtenido un total de 137 respuestas para un tamaño muestral de 278 Sociedades Locales de Cazadores Federadas y que formarán parte de futuras investigaciones en esta línea. En este caso, el error muestral más desfavorable se reduce al $6 \%$ de los casos y al 3,6\% en la situación más favorable.

Tabla 2. Ficha técnica de las encuestas realizadas

\begin{tabular}{|c|c|c|}
\hline Encuesta: & Perfil del turista cinegético & Sociedades Locales de Cazadores \\
\hline Universo: & $\begin{array}{l}40887 \text { (licencias expedidas de } \\
\text { caza, 2017) }\end{array}$ & $\begin{array}{l}278 \text { (sociedades locales de cazadores federadas } \\
\text { en Extremadura en 2017) }\end{array}$ \\
\hline $\begin{array}{l}\text { Tamaño de la } \\
\text { muestra: }\end{array}$ & $\begin{array}{l}82 \text { (número de personas } \\
\text { encuestadas) }\end{array}$ & $\begin{array}{l}138 \text { (número de sociedades que han } \\
\text { cumplimentado el cuestionario) }\end{array}$ \\
\hline Muestreo: & \multicolumn{2}{|l|}{ Aleatorio Simple } \\
\hline Nivel de confianza: & \multicolumn{2}{|r|}{$95 \%$} \\
\hline Tipo de encuesta: & $\begin{array}{l}\text { Cuestionario impreso } \\
\text { cumplimentado por los turistas } \\
\text { que han pasado por las oficinas } \\
\text { de turismo localizadas por todo el } \\
\text { territorio extremeño. }\end{array}$ & $\begin{array}{l}\text { Cuestionario dispuesto en Google Drive, } \\
\text { cumplimentado por los presidentes de las } \\
\text { Sociedades Locales de Cazadores Federadas. }\end{array}$ \\
\hline $\begin{array}{l}\text { Error muestral para } \\
\text { el escenario más } \\
\text { desfavorable }(p q=50) \\
\text { y más favorable } \\
(p q=90 \%)\end{array}$ & $10,8 \% / 6,5 \%$ & $6 \% / 3,6 \%$ \\
\hline Fecha de realización: & $\begin{array}{l}1 \text { de enero de } 2017 \text { a } 31 \text { de } \\
\text { diciembre de } 2017\end{array}$ & 15 de febrero de 2018 a 15 de junio de 2018 \\
\hline
\end{tabular}

Fuente: Elaboración Propia

Para el desarrollo de este trabajo se han aplicado diversas técnicas. En primer lugar, se procedió a realizar un repaso de la bibliografía específica para estimar la situación en la que se encuentra la caza en Extremadura y conocer los estudios que han abordado la temática cinegética desde distintas perspectivas. En segundo lugar, mediante técnicas estadísticas de carácter univariante y descriptivo, concretamente, la distribución de frecuencias tanto absolutas como relativas, se realizó el tratamiento de los datos procedentes del Observatorio de 
Turismo de Extremadura. Asimismo, se han utilizado los Sistemas de Información Geográfica para representar algunas de las variables como es el caso de las procedencias de los turistas nacionales, permitiendo visualizar la importancia de la cercanía a la hora de realizar un desplazamiento motivado por la actividad cinegética. En la misma línea se han realizado mapas temáticos en los que se identifica la gran movilidad que realiza el turista cinegético por toda la región.

Estas técnicas han sido empleadas en otros trabajos cuya temática se centra en la caza. Desde una panorámica internacional cabe mencionar el informe elaborado por el Us Fishing and Wildlife Service, organismo que realiza cada cinco años una Encuesta Nacional sobre pesca, caza y actividades en contacto con la naturaleza. En ella se mide el impacto que tienen algunas variables relacionadas con la movilidad de cazadores en Estados Unidos (Interior, Service y Commerce, 2016). Desde una perspectiva nacional destaca el ya añejo estudio realizado por METRA SEIS (1985) donde la metodología empleada se fundamentó en los datos recopilados a través de la divulgación de cuestionarios y la realización de entrevistas personales. Finalmente, a escala regional es reseñable el trabajo de Nogueras, Caridad y Gálvez (2017) en el que a partir de la difusión de un cuestionario se pudo concretar el perfil del turista cinegético en la provincia de Córdoba.

\section{SITUACIÓN DE LA CAZA EN EXTREMADURA}

La presente investigación se enmarca geográficamente en la comunidad autónoma de Extremadura, región en la que durante el año 2017 se expidieron un total de 40887 licencias de caza (Gallardo et al., 2018), cifra representativa pero que muestra una tendencia a la baja desde el año 2007, tal y como se aprecia en el Gráfico 1 . No obstante, hay que matizar que este dato se incrementa de forma sustancial si se tienen en cuenta las licencias en vigor, habida

Gráfico 1. Evolución de licencias de caza expedidas en Extremadura

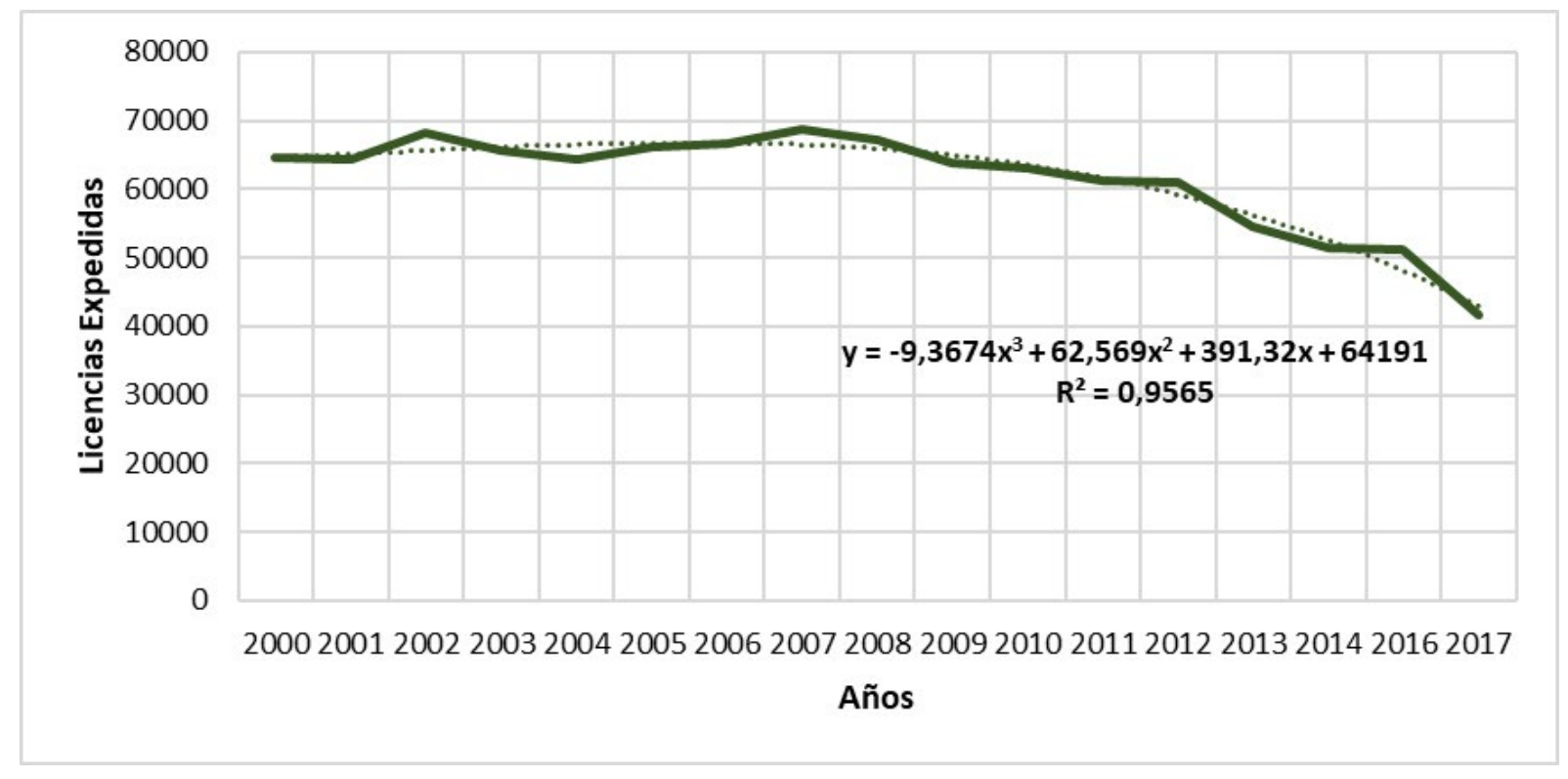

Fuente: Junta de Extremadura (Varios años) 
cuenta de que existe la posibilidad de solicitar la licencia por un periodo superior a un año. Si se tiene en cuenta dicha circunstancia el número de licencias se eleva a la cifra de 88885 , de acuerdo con los últimos datos publicados en el informe anual elaborado por la Federación Extremeña de Cazadores (2018). Esta es una de las razones por la que, a veces, las estadísticas ofrecidas por las autoridades competentes pueden resultar confusas.

Como dato complementario, parece oportuno aludir al volumen de cazadores federados en Extremadura, cuya evolución está marcada por un leve descenso tras comparar el número de cazadores federados en 1997 (18 820) y los del año 2018 (17 049) (Federación Extremeña de Caza, 2019). A pesar de ello, cabe mencionar que, en los próximos años, este número experimentará un previsible incremento, ya que, entre las modificaciones que recoge la Ley de Caza que ha sido aprobada recientemente en la Asamblea de Extremadura, se establece la obligatoriedad de poseer la condición de federado para cazar en cotos sociales (Propuesta de ley por la que se modifican la ley 14/2010, de 9 de diciembre de caza en Extremadura y la ley $18 / 2001$, de 14 de diciembre, sobre tasas y precios públicos de la comunidad autónoma de Extremadura). En este sentido hay que recordar que estos terrenos cinegéticos abarcan algo más del 49\% de la extensión acotada en Extremadura (Gallardo et al., 2018).

Independientemente de la cifra absoluta de licencias existentes, es indudable que la caza en Extremadura es una actividad que cuenta con un gran arraigo, particularidad que viene impulsada por la confluencia de factores de diferente índole. Terrón (1975) destaca las características del paisaje y Alvarado (1991) y Rengifo (2012) enumeran un conjunto de elementos de carácter histórico, ambiental, económico y social. En el contexto actual, uno de los datos que acredita la vitalidad del sector de la caza en la región hay que relacionarlo con la proporción de superficie que adquiere la consideración de terreno cinegético, al alcanzar la sobresaliente cifra del $87 \%$ del total regional. No obstante, esta cifra no es una excepción en el panorama cinegético nacional, en la que la mayor parte de las comunidades autónomas presentan dígitos muy elevados en esta materia (Andueza et al., 2018a).

La normativa vigente clasifica los terrenos cinegéticos bajo tres categorías, cuyas denominaciones son las siguientes: terrenos bajo gestión pública, cotos de caza y zonas de caza limitada. Dentro de estas categorías coexisten, a su vez, diferentes clases y tipos. Esta categorización contiene, asimismo, una peculiaridad que ha caracterizado a la caza en Extremadura desde el año 1990: la coexistencia de dos modelos de aprovechamiento diferenciados (el social y el económico). Ambos enfoques, social y económico, se convirtieron en seña de identidad y principio cardinal desde la aprobación de la primera ley de caza autonómica, tal y como sucesivamente se fue recogiendo en las diferentes exposiciones de motivos de las leyes de caza: "Como principio básico de este nuevo ordenamiento, se fija el doble reconocimiento de la caza como actividad social y económica. Distinción que pretende dar cobertura a esta actividad cuando va asociada a la cultura y al ocio, y que se organiza en Sociedades Locales, al tiempo que como actividad económica aporta alternativas y complemento al desarrollo y empleo rural" (Ley 14/2010). Como consecuencia de ello, la relevancia de los cotos sociales ha alcanzado en Extremadura una sobresaliente dimensión que se manifiesta en el número de hectáreas afectadas por esta figura que, durante el año 2017, alcanzaba la sobresaliente cifra de 1717572 ha, lo que supone el 49,44\% del total de la superficie destinada a la práctica 
cinegética. Por su parte, el modelo destinado al lucro o aprovechamiento privado, representado por las diferentes figuras de cotos, alcanza una dimensión parecida, pues tal cifra se sitúa en términos absolutos en 1756442 has, lo que supone el 50,56\% del total de los terrenos cinegéticos acotados.

Tabla 3. Clasificación de terrenos cinegéticos acotados en Extremadura (2017)

\begin{tabular}{|l|c|}
\hline \multicolumn{1}{|c|}{ TIPO DE COTO } & SUPERFICIE (HA) \\
\hline Privado de Caza Mayor Abierto más Intensivo Caza Menor & 24236 \\
\hline Privado de Caza Mayor Abierto & 499085 \\
\hline Privado de Caza Mayor Cerrado & 169105 \\
\hline Privado de Caza Mayor Cerrado más Intensivo de Caza Menor & 7011 \\
\hline Privado de Caza Menor más Jabalí & 329702 \\
\hline Privado de Caza Menor Extensivo & 638968 \\
\hline Privado de Caza Menor Intensivo & 87335 \\
\hline Social o Local & 1717572 \\
\hline TOTAL & 3473014 \\
\hline
\end{tabular}

Fuente: Elaboración propia a partir de datos de la Federación Extremeña de cazadores.

Por último, existen otras tipologías de terrenos cinegéticos que son gestionadas por la administración pública y que, a pesar de su escasa importancia territorial, es necesario tenerlos en cuenta, ya que turistas cinegéticos practican el ejercicio de las artes venatorias en este tipo de terrenos. Durante la temporada 2017/18 los terrenos gestionados por la Junta de Extremadura estaban conformados por dos reservas de caza (Reserva de Caza La Sierra y Reserva de Caza del Cíjara) y tres Cotos Regionales (Cañamero, Gargantillas y Matallana). Para la próxima temporada 2019/2020 han sido sorteados un total de 494 permisos de caza en estos terrenos. De ellos, 246 se han destinado a cazadores locales (cazadores residentes en los municipios en los que se ubican estos terrenos), 198 a cazadores autonómicos (residentes dentro de la comunidad autónoma) y 50 a cazadores nacionales (residentes en otra comunidad autónoma) (Resolución de 12 de febrero de 2019, de la Consejera, por la que se aprueba la oferta pública de caza, se elevan a definitivos los listados de admitidos al sorteo y se determina la fecha de celebración del mismo).

Sobre el conjunto de terrenos cinegéticos de Extremadura existe la posibilidad de abatir una amplia relación de especies de caza menor (24) y caza mayor (7), de acuerdo con lo dictado en la última orden sobre los periodos hábiles de caza en la región. Desde el punto de vista estadístico, la Tabla 4 recoge el número de capturas de las especies más representativas, tanto de caza mayor como menor. De entre las de caza menor destacan los resultados concernientes a la perdiz roja, y en relación con las especies de caza mayor sobresalen las capturas de ciervo y el jabalí. En los últimos años se ha constatado una mayor expansión geográfica de las especies de caza mayor (ciervo y jabalí) y un estancamiento, o disminución, de las de caza menor (Rengifo, 2012). 
Tabla 4. Número de capturas por especie (2016/17)

\begin{tabular}{|l|r|}
\hline & NÚMERO DE CAPTURAS \\
\hline ESPECIES DE CAZA MENOR & 266263 \\
\hline Perdiz Roja & 57019 \\
\hline Conejo & 77346 \\
\hline Liebre & \\
\hline ESPECIES DE CAZA MAYOR & 36764 \\
\hline Ciervo & 24165 \\
\hline Jabalí & 4761 \\
\hline Otros & $\mathbf{4 6 6 3 1 8}$ \\
\hline TOTAL & \\
\hline
\end{tabular}

Fuente: Elaboración propia a partir de datos de la Federación Extremeña de Caza

En síntesis, esta concisa radiografía de la caza en Extremadura muestra la fortaleza que posee dicha actividad en la región, compartiendo un mismo escenario geográfico con otras actividades de carácter tradicional como la agricultura y la ganadería.

\section{EL TURISMO CINEGÉTICO EN EXTREMADURA}

Desde la asunción de competencias, por parte de la Junta de Extremadura, en el año 1983, el sector turístico en Extremadura ha experimentado un notable desarrollo que lo ha convertido, no solo en un sector económico con capacidad para crear empleo y riqueza, sino en una actividad que contribuye a potenciar la imagen de Extremadura a nivel nacional e internacional (Rengifo, 2013). Como consecuencia de ello, el turismo se ha convertido en un sector que, de acuerdo con estimaciones recientes, aporta al PIB regional una cifra del 5,6\% y un volumen de empleo que sobrepasa la cifra de 23000 trabajadores (Junta de Extremadura, 2017). Esta es una de las razones por las que este sector despierta un gran interés, tanto en los municipios de mayor peso demográfico como en los de menor tamaño.

Durante el periodo comprendido entre los años 1983 y 2017, la administración regional ha ido tejiendo y aprobando una normativa propia que se ha modificado en varias ocasiones, al tiempo que ha impulsado planes de intervención turística de diferente naturaleza, ejecutado políticas de promoción y consensuados planes estratégicos, dentro de los cuales está el vigente Plan Turístico de Extremadura 2017-2020 (Junta de Extremadura, 2017). En este plan se priorizan una serie de segmentos y se tiene en cuenta al turismo cinegético como modalidad específica que se inserta en otra de carácter más genérico, como es la del turismo deportivo y de aventura.

En este sentido, el turismo cinegético se identifica con una modalidad específica ligada al medio rural, a la que se le atribuye cierta capacidad para contribuir a la dinamización de las economías rurales. Por este motivo, diferentes actores públicos y privados señalan el interés de la caza como herramienta de desarrollo. Un ejemplo de ello se encuentra en la Estrategia Española de Desarrollo Sostenible (2007) en la que se recoge la importancia de la caza y la pesca como motores de desarrollo en el medio rural español. Asimismo, en el campo de las 
investigaciones científicas existen trabajos que establecen una relación entre la caza y el desarrollo, ya sea como actividad complementaria de la actividad ganadera y forestal (Bardají, 1987; Bielsa, 1987; Urquijo, 1987) o como potencial producto turístico (Mulero, 1991; Calvo, 2002; Danzberger, 2009).

En el caso extremeño, el montante económico generado por la actividad cinegética se estima en 385 millones de euros, de acuerdo con lo recogido en el último informe publicado por la Federación Extremeña de Caza para la temporada de caza 2016/17 (Gallardo et al., 2018). Esta cifra queda empequeñecida por el impacto de la caza en Castilla la Mancha, estimado en 604 millones de euros (Andueza et al., 2018b) y en los 6475 millones de euros estimados para el conjunto de España (Andueza et al., 2018a).

En cualquiera de los informes citados anteriormente se expresa el indudable impacto que tiene la caza en los sectores del alojamiento y restauración. Profundizando en esta materia, habría que añadir, además, que la demanda de estos servicios turísticos se produce en un periodo en el que el número de turistas decrece (Danzberger, 2009). Dicha demanda se lleva a cabo en el contexto de los desplazamientos que hacen lo cazadores para practicar la actividad venatoria. En este sentido, diferentes trabajos remarcan la existencia de tres tipos de cazadores, conformados por porcentajes muy variables, en función de sus desplazamientos: cazadores regionales, cazadores nacionales y cazadores internacionales (Pinet, 1995; Hofer 2002, Rengifo, 2008, 2011, 2013).

Los datos existentes de Extremadura expresan que, en el bloque de cazadores nacionales e internacionales, podría integrarse el $25 \%$ de los poseedores de licencias a nivel regional (Rengifo 2008, 2013). Al mismo tiempo, hay que hacer notar que Extremadura se encontraría entre los destinos más solicitados, de acuerdo con lo recogido en el informe de Andueza et al. (2018a.). De hecho, del total de licencias expedidas en Extremadura durante la temporada de caza 2016/17, 6939 fueron destinadas a cazadores que residen fuera de la región extremeña (Gallardo et al., 2018).

\section{APROXIMACIÓN AL PERFIL DEL TURISTA CINEGÉTICO EN EXTREMADURA}

\subsection{Caracterización sociodemográfica}

En la aproximación al perfil del turista cinegético resulta interesante analizar las características sociodemográficas del turista cinegético en Extremadura mediante tres variables: género, edad y procedencia. En este sentido, llama la atención, en primer lugar, que las personas que responden a la encuesta muestren un equilibro procentual en lo que se refiere a género, dato que contrasta con la realidad de las personas que cuentan con licencia que son, mayoritariamente hombres. En el estudio realizado por la Federación Extremeña de Caza, donde se hace referencia al perfil del cazador extremeño, por ejemplo, se pone de manifiesto que en Extremadura más del 95\% de los cazadores son hombres (Gallardo et al., 2018). El elevado porcentaje de mujeres que responden a la encuesta puede deberse a numerosas causas. Una de ellas puede derivarse del hecho de que se definan como turistas cinegéticos todas las personas cuya motivación principal de desplazamiento sea la caza, independientemente de si la practican directamente o son acompañantes. De hecho, de acuerdo con los 
datos recopilados en este trabajo se constata que la mayor parte de los cazadores viajan acompañados, fundamentalmente en pareja.

Por otra parte, de los datos obtenidos se desprende que el turista de caza pertenece fundamentalmente al grupo de edad situado entre los 46 y 55 años, identificándose como un turista maduro y asentado económicamente, frente a una escasa presencia del turista joven, menor de 25 años. Esta situación no se presenta de manera exclusiva en la comunidad extremeña, sino que entre la literatura se encuentran casos como el referido por Nogueras, Caridad y Gálvez (2017) en el que se afirma que, en la provincia de Córdoba, el grupo etario más representativo de turistas cinegéticos es aquel que presenta entre 50 y 59 años. Complementariamente, se detecta una escasa incidencia del turista mayor de 65 años, hecho que coincide con el perfil del cazador en Extremadura, donde tan sólo el 2,4\% pertenece a este grupo etario (Gallardo et al., 2018)

El turismo cinegético es un fenómeno que ha experimentado un notorio crecimiento tanto a nivel nacional como internacional (Rengifo, 2008). En esta línea, los resultados obtenidos corroboran la importancia del turista internacional que representa el $17,1 \%$ del total de los encuestados, frente al 82,9\% de procedencia nacional. Tal situación puede verse motivada por la mayor tendencia del turista internacional a acudir a las oficinas de información turística con objeto de recopilar información, coincidiendo con el lugar de difusión de la encuesta que ha generado estos datos.

Tabla 5. Características sociodemográficas 2017

\begin{tabular}{|l|c|}
\hline \multicolumn{1}{|c|}{ ÍTEMS } & RESPUESTAS \\
\hline Mujer & \\
\hline Hombre & $47,6 \%$ \\
\hline NS/NC & $51,2 \%$ \\
\hline \multicolumn{1}{|c|}{ EDAD } & $1,2 \%$ \\
\hline Entre 18 y 25 años & $6,1 \%$ \\
\hline Entre 26 y 35 años & $22,0 \%$ \\
\hline Entre 36 y 45 años & $19,5 \%$ \\
\hline Entre 46 y 55 años & $34,1 \%$ \\
\hline Entre 56 y 65 años & $15,9 \%$ \\
\hline Más de 65 años & $2,4 \%$ \\
\hline PROCEDENCIA & \\
\hline Nacionales & $82,9 \%$ \\
\hline Extranjeros & $17,1 \%$ \\
\hline
\end{tabular}

Fuente: Elaboración Propia

Un análisis más exhaustivo de la muestra de turistas nacionales permite apreciar la importancia que tiene la proximidad geográfica en esta modalidad, avalada por el hecho de que la mayor parte de turistas residen en provincias limítrofes y bien comunicadas por carretera con la región extremeña, fundamentalmente Madrid y Sevilla. Estos datos son contrastables 
con los proporcionados por el informe de la Federación Extremeña de Caza, en los que se muestra como el $50 \%$ de las licencias expedidas a cazadores foráneos, durante la temporada de caza 2016/17, pertenece a personas residentes en ambas provincias (Gallardo et al., 2018). En esta muestra de turistas nacionales puede apreciarse, complementariamente, la incidencia del turista autonómico entendiendo como tal a aquel que reside en el propio territorio extremeño y que se desplaza por toda la región con motivo de la práctica cinegética

Figura 1. Origen de los turistas cinegéticos españoles

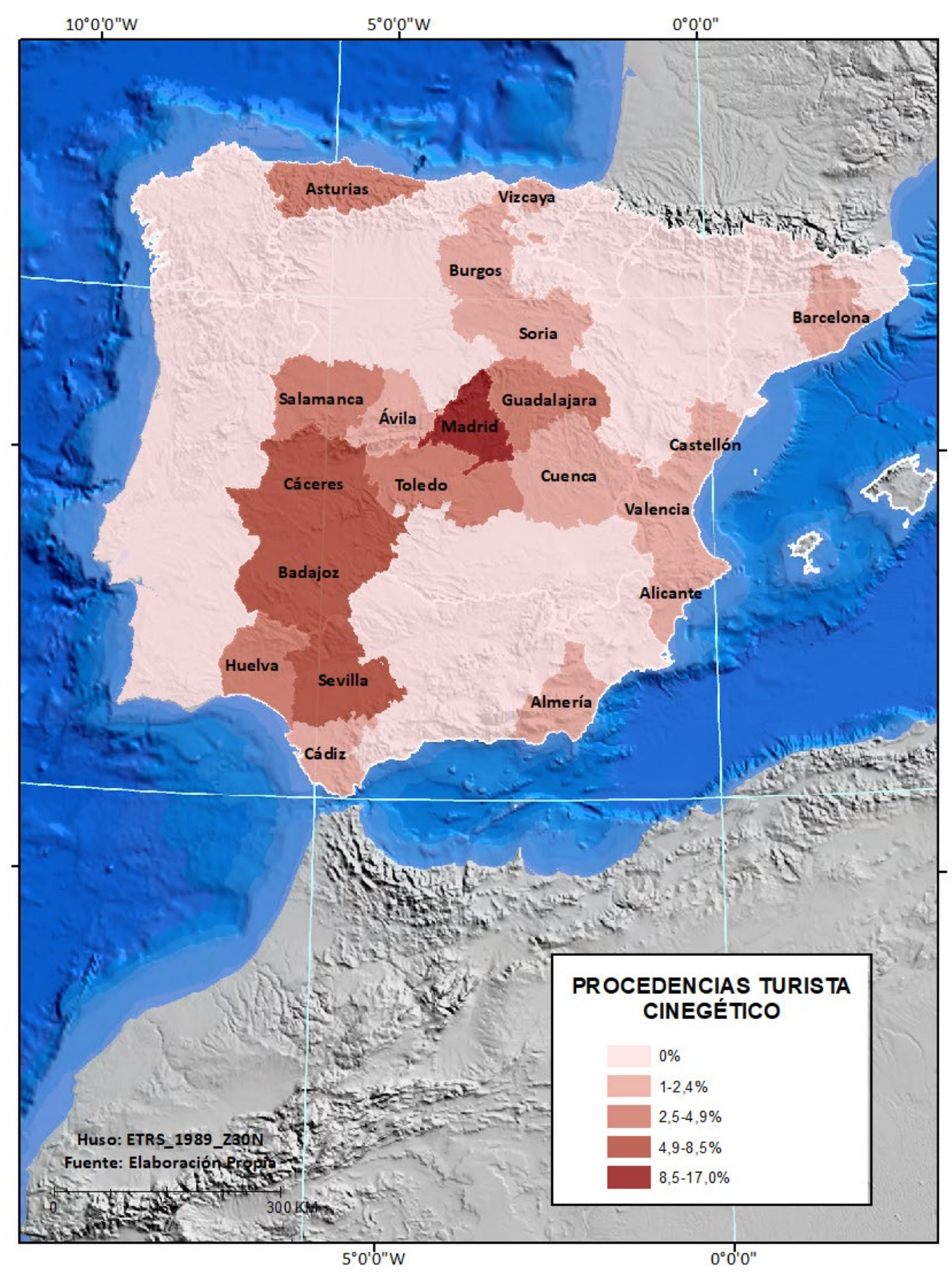

\subsection{Caracterización del viaje}

El viaje que emprende el turista cinegético hacia Extremadura con motivo de la práctica de las artes venatorias comprende diversas actividades que, para nada, se limitan al propio 
acto de caza, sino que se identifican como parte de otras modalidades turísticas entre las que cabe reseñar el turismo cultural y el rural. En este complejo entramado de actividades sobresale el notable interés por el patrimonio cultural que manifiesta este tipo de turistas, dando lugar a que las visitas culturales se presenten como una de las principales actividades realizadas durante el viaje. En la misma línea, identificándose como otra de las ocupaciones predilectas por el turista cinegético aparecen aquellas ligadas al disfrute de la gastronomía propias de la zona, que abarcan al $60,2 \%$ de la muestra. Con una menor incidencia, aparece la práctica del turismo rural realizada por algo más de la mitad de los turistas de caza. Una de las características propias de la práctica cinegética es su desarrollo durante los meses invernales, lo que conduce a que otras actividades sujetas a condiciones climáticas propias de otras estaciones tengan una menor cabida entre el sector cinegético, tales como el turismo de baño, la observación del cielo o las prácticas deportivas. Estos datos no hacen más que atestiguar la potencialidad que presenta el turismo cinegético como complemento de otras modalidades turísticas más asentadas como sería el turismo rural. Precisamente, este tipo de turismo se caracteriza por su elevada estacionalidad, tal y como muestran los datos de pernoctaciones en Extremadura en el año 2017, donde se produjo un descenso del número de pernoctaciones en alojamientos rurales, desde las 74877 en en el mes de agosto a las 30348 en el mes de octubre (INE, 2017).

Tabla 6. Actividades que realiza durante el viaje

\begin{tabular}{|l|c|}
\hline \multicolumn{1}{|c|}{ ACTIVIDAD } & RESPUESTAS \\
\hline Caza & $100 \%$ \\
\hline Visitas Culturales & $62,7 \%$ \\
\hline Gastronomía & $60,2 \%$ \\
\hline Turismo rural & $53,0 \%$ \\
\hline Observación de aves & $25,3 \%$ \\
\hline Turismo en ríos y gargantas o embalses & $22,9 \%$ \\
\hline Visitas a bodegas & $21,7 \%$ \\
\hline Visitar minas y formaciones geológicas & $19,3 \%$ \\
\hline Observación del cielo & $12,0 \%$ \\
\hline Practicar deporte & $8,4 \%$ \\
\hline Participar en eventos (congresos o reuniones) & $8,4 \%$ \\
\hline Visitar escenarios de películas o series TV & $2,4 \%$ \\
\hline
\end{tabular}

Fuente: Elaboración Propia

La actividad cinegética se presenta en el contexto europeo como una actividad con un marcado carácter colectivo, siendo minoritaria la caza en solitario (Pinnet, 1995; p.3). Este hecho es papable en los datos de la Tabla 7 donde se identifica el viaje del turista cinegético como una actividad que se realiza en pareja, con familiares o con amigos, teniendo una escasa presencia el turista solitario o en grupos organizados. Este dato aporta una interesante información sobre la capacidad de atracción que presenta la actividad cinegética, ya que no se limita al mero viaje del cazador solitario, sino que es acompañado por personas que pueden ser ajenas a la práctica cinegética y que realizan otro tipo de actividades como aquellas ligadas 
al turismo rural o cultural. Con respecto a la pregunta de tipo múltiple sobre el medio de organización del viaje, internet y las recomendaciones de amigos o familiares se identifican como los medios más utilizados, teniendo una escasa representatividad otras más tradicionales como las agencias de viajes u otro tipo de medios.

Los días hábiles para la práctica cinegética en la temporada 2016/17, a los que habría que sumar las excepciones previstas normativamente, se concentraban en sábados, domingos y festivos nacionales o regionales, salvo en algunas modalidades específicas como la paloma en puesto fijo o la liebre con galgos en los que se ampliaba al jueves. Esta situación general condiciona la duración de las estancias medias que realiza el turista cinegético, con un promedio que se sitúa en el abanico de dos a cuatro noches. Estas estancias suelen realizarse en hoteles entre 1 y 3 estrellas (24,4\%), en casa de familiares o amigos (22\%) o en alojamientos rurales (15\%), teniendo una escasa repercusión en aquellos hospedajes con una categoría oscilante entre 4 o 5 estrellas. Tal situación viene determinada por dos puntos claves: la predilección del turista cinegético por alojamientos que se encuentran situados cerca del coto en el que realizará la practica cinegética, así como la escasa oferta de alojamientos de una mayor categoría en las localidades predilectas para la pernoctación por este tipo de turistas. De hecho, en el caso de la localidad de Azuaga, la cual aparece como el lugar donde mayor número de turistas cinegéticos pernocta, de acuerdo con los datos de la encuesta, no existen hoteles entre 4 y 5 estrellas, sino que la oferta se limita a otras tipologías como el hostal, la casa rural, el apartamento turístico o el hotel entre 1 y 3 estrellas. Esta situación se repite en las localidades de Villanueva de la Serena o Plasencia, si bien esta última localidad es la que mayor número de hoteles de 4 estrellas oferta, aunque, sin embargo, tal cifra se reduce al $16,6 \%$ del total de la oferta si se tienen en cuenta todos los alojamientos turísticos que se ubican en ella.

Tabla 7. Caracterización del viaje

\begin{tabular}{|c|c|c|c|c|c|c|c|}
\hline & En pareja & En familia & $\begin{array}{c}\text { Con } \\
\text { amigos }\end{array}$ & $\begin{array}{l}\text { En grupos } \\
\text { organizados }\end{array}$ & Solo/a & NS/NC & \\
\hline \multirow[t]{2}{*}{$\begin{array}{l}\text { ¿Con quién } \\
\text { viaja? }\end{array}$} & $36,6 \%$ & $26,8 \%$ & $24,4 \%$ & $4,9 \%$ & $6,1 \%$ & $1,2 \%$ & \\
\hline & Internet & Recomendación & $\begin{array}{l}\text { Agencia } \\
\text { de } \\
\text { Viajes }\end{array}$ & $\begin{array}{l}\text { Medios de } \\
\text { Comunicación }\end{array}$ & Otros & & \\
\hline \multirow{2}{*}{$\begin{array}{l}\text { Medio de } \\
\text { organización } \\
\text { del viaje }\end{array}$} & $35,4 \%$ & $8,5 \%$ & $6,1 \%$ & $2,4 \%$ & $6,1 \%$ & & \\
\hline & $\begin{array}{l}\text { Una } \\
\text { noche }\end{array}$ & Dos noches & $\begin{array}{c}\text { Tres } \\
\text { noches }\end{array}$ & Cuatro noches & $\begin{array}{l}\text { Cinco } \\
\text { noches }\end{array}$ & $\begin{array}{l}\text { Más de } \\
\text { cinco } \\
\text { noches }\end{array}$ & $\mathrm{NS} / \mathrm{NC}$ \\
\hline \multirow[t]{2}{*}{ Pernoctación } & $7,3 \%$ & $23,2 \%$ & $12,2 \%$ & $15,9 \%$ & $4,9 \%$ & $14,5 \%$ & $22 \%$ \\
\hline & $\begin{array}{l}\text { Hotel } \\
\text { de } 4 \text { a } 5 \\
\text { estrellas }\end{array}$ & $\begin{array}{l}\text { Hotel entre } 1 \text { y } 3 \\
\text { estrellas }\end{array}$ & $\begin{array}{l}\text { Hostal o } \\
\text { pensión }\end{array}$ & $\begin{array}{c}\text { Alojamiento } \\
\text { rural }\end{array}$ & $\begin{array}{c}\text { Casa de } \\
\text { familiares } \\
\text { o amigos }\end{array}$ & Otros & $\mathrm{NS} / \mathrm{NC}$ \\
\hline $\begin{array}{l}\text { Tipo de } \\
\text { alojamiento }\end{array}$ & $7,3 \%$ & $24,4 \%$ & $9,8 \%$ & $15,9 \%$ & $22,0 \%$ & $6,1 \%$ & $14,5 \%$ \\
\hline
\end{tabular}

Fuente: Elaboración Propia 
El turista cinegético aporta cuantiosos beneficios económicos a la región extremeña que no se limitan al acto de caza, sino que vienen relacionados con el disfrute del entorno mediante el gasto en hospedaje, así como en otras actividades como la gastronomía presente en los establecimientos de restauración y otros derivados de la adquisición de recuerdos o productos de distinta índole. Por ello, se aprecia la necesidad de abordar la temática económica mediante una estimación al gasto medio diario efectuado por este turista teniendo en cuenta los generados mediante las principales actividades: el alojamiento como medida de gasto en pernoctación, la alimentación identificando el realizado en la gastronomía, así como aquel derivado de otro tipo de compras entre las que se encuentra la adquisición de todo tipo de productos y recuerdos. En el primero de los casos, el gasto medio diario en alojamiento se estima como reducido, derivado de dos aspectos clave. Por un lado, la incidencia de la pernoctación en casa de familiares o amigos lleva a que casi el $20 \%$ de los encuestados no realice ningún tipo de gasto en alojamiento, provocando la reducción del gasto medio. En este mismo sentido, se manifiesta la preferencia por hospedajes más económicos como son el hotel entre 1 y 3 estrellas, así como el alojamiento rural o el hostal y la pensión, frente a un escaso número de turistas que se alojan en hoteles de 4 y 5 estrellas. En contraposición se atestigua la importancia del disfrute gastronómico entre los turistas cinegéticos que provoca que el gasto medio diario destinado a alimentación ascienda a un promedio de 35,3 euros, superando al realizado en el alojamiento. En este mismo sentido aparece el gasto derivado de otras compras entre las que pueden encontrarse la adquisición de productos de recuerdo, siendo mayor que el gasto destinado al hospedaje, y es que, el turista cinegético realiza un gasto medio diario destinado a otras compras de 33,9 euros.

Tabla 8. Gasto medio diario por persona

\begin{tabular}{|l|c|c|c|}
\hline & Alojamiento & Alimentación & Compras \\
\hline Sin gasto & $19,5 \%$ & & $3,7 \%$ \\
\hline De 1 a 10€ & $2,4 \%$ & $8,5 \%$ & $8,5 \%$ \\
\hline De 11 a 20€ & $3,7 \%$ & $12,2 \%$ & $20,7 \%$ \\
\hline De 21 a 30€ & $14,6 \%$ & $25,6 \%$ & $23,2 \%$ \\
\hline De 31 a 40€ & $15,9 \%$ & $14,6 \%$ & $7,3 \%$ \\
\hline De 41 a 50€ & $12,2 \%$ & $8,5 \%$ & $4,9 \%$ \\
\hline De 51 a 60€ & $4,9 \%$ & $6,1 \%$ & $4,9 \%$ \\
\hline Más de 60€ & $12,2 \%$ & $13,4 \%$ & $12,2 \%$ \\
\hline Promedio de gasto & 32,2 euros & 35,3 euros & 33,9 euros \\
\hline
\end{tabular}

Fuente: Elaboración Propia

\subsection{Principales movimientos del turista cinegético}

La riqueza cinegética que caracteriza a la región extremeña lleva al turista de caza a pernoctar en una amplia red de localidades como presenta la Figura 2. Entre ellas destacan localidades como Azuaga o Villanueva de la Serena, siendo la primera de ellas protagonista de una de las mayores monterías extremeñas, la Gran Montería de la Sierra de Azuaga, que cada año acoge a un mayor número de cazadores (Periódico Extremadura, 2017). Continuando con la tradición cinegética se encuentra el municipio de Herrera del Duque, situado sobre la Reserva 
Regional del Cíjara, la cual destaca por la presencia de especies cinegéticas muy demandadas como el gamo (Dama dama) o el corzo (Capreolus capreolus) que llevan a su elección como lugar de pernoctación por parte del turista de esta modalidad (Gallardo et al., 2018). Lo mismo ocurre con las localidades de Alcántara y Cáceres ubicadas bajo los dominios de la tradicional comarca cinegética de la Sierra de San Pedro en la que, fundamentalmente, se practica la caza mayor (Junta de Extremadura, 2015). Por otro lado, ciudades con una gran riqueza cultural aparecen con una menor relevancia en la pernoctación como Plasencia, Mérida, Trujillo, Guadalupe o Zafra, pero que, sin embargo, aparecen entre las localidades más visitadas por este tipo de turista debido al interés del visitante por el patrimonio cultural.

El turista cinegético se presenta, además, como un gran apasionado de la naturaleza, lo que motiva que durante su estancia en Extremadura no se limite a la práctica de las artes venatorias, sino que se realicen otro tipo de actividades ligadas a conocer el rico patrimonio natural del que dispone dicha región. No es de extrañar este interés por estos Espacios Naturales Protegidos teniendo en cuenta que muchos de ellos se sitúan en zonas en las que tradicionalmente ha primado la práctica de las artes venatorias (Rengifo y Sánchez, 2016). Este comportamiento se aprecia en la Figura 2, donde se señalan las visitas de los turistas cinegéticos en Extremadura a los diferentes Espacios Naturales Protegidos que posee la región. Entre ellos sobresalen cuatro, el Parque Nacional de Monfragüe, la Reserva de la Garganta de los Infiernos, los Barruecos y el Parque Natural Tajo Internacional. De ellos, el Parque Nacional de Monfragüe es el más visitado por el turista cinegético, posiblemente porque este Espacio Natural Protegido muestra una gran capacidad de atracción por multitud de perfiles de visitantes como recoge el análisis realizado por Sánchez y Rengifo (2017). En dicho trabajo, además, se reflejan los límites de la atracción turística de Monfragüe que quedan condicionados por el tiempo de desplazamiento al mismo. Bajo estas circunstancias, no es de extrañar la frecuencia de visitas de los turistas cinegéticos hacia este espacio, debido a que una gran parte de los encuestados eligieron la localidad de Plasencia como lugar de pernoctación (Figura 2), cuyo desplazamiento hasta este Espacio Natural Protegido se reduce a 28 minutos de duración (Guía Michelín, 2018). Este mismo patrón se observa en relación con las visitas a la Garganta de los Infiernos, espacio natural situado en el municipio de Cabezuela del Valle, el cual se caracteriza por estar inserto en un área por la que se distribuye una de las especies cinegéticas de caza mayor más emblemáticas de la región: la cabra montés (Capra pyrenaica). A este hecho hay que añadir la localización de este espacio, teniendo en cuenta que gran parte de los turistas encuestados pernoctaron en localidades próximas a él: Plasencia, cuya ruta óptima marca un tiempo de desplazamiento de 34 minutos (Guía Michelín, 2018), o Hervás, desde donde se registra una duración del viaje hacia este Espacio Natural Protegido de 48 minutos (Guía Michelín, 2018). Por esta misma razón, el Parque Natural del Tajo Internacional, a pesar de su cercanía a una de las zonas tradicionales de caza, como es la Sierra de San Pedro (Rengifo y Sánchez, 2016), recibió un menor número de turistas cinegéticos (11\%). En el caso de los Barruecos, sus visitas pueden verse motivadas en primer lugar por su cercanía a la comarca cinegética de la Sierra de San Pedro y, en segundo lugar, debido a la localización de este espacio natural sobre una de las ciudades predilectas para la pernoctación por el turista cinegético, la ciudad de Cáceres. 
A la luz de estos datos se puede concluir que los turistas cinegéticos se caracterizan por una notoria movilidad, circunstancia que provoca que se produzca un mayor reparto del gasto por toda la región.

Figura 2. Localidades de pernoctación y visitas

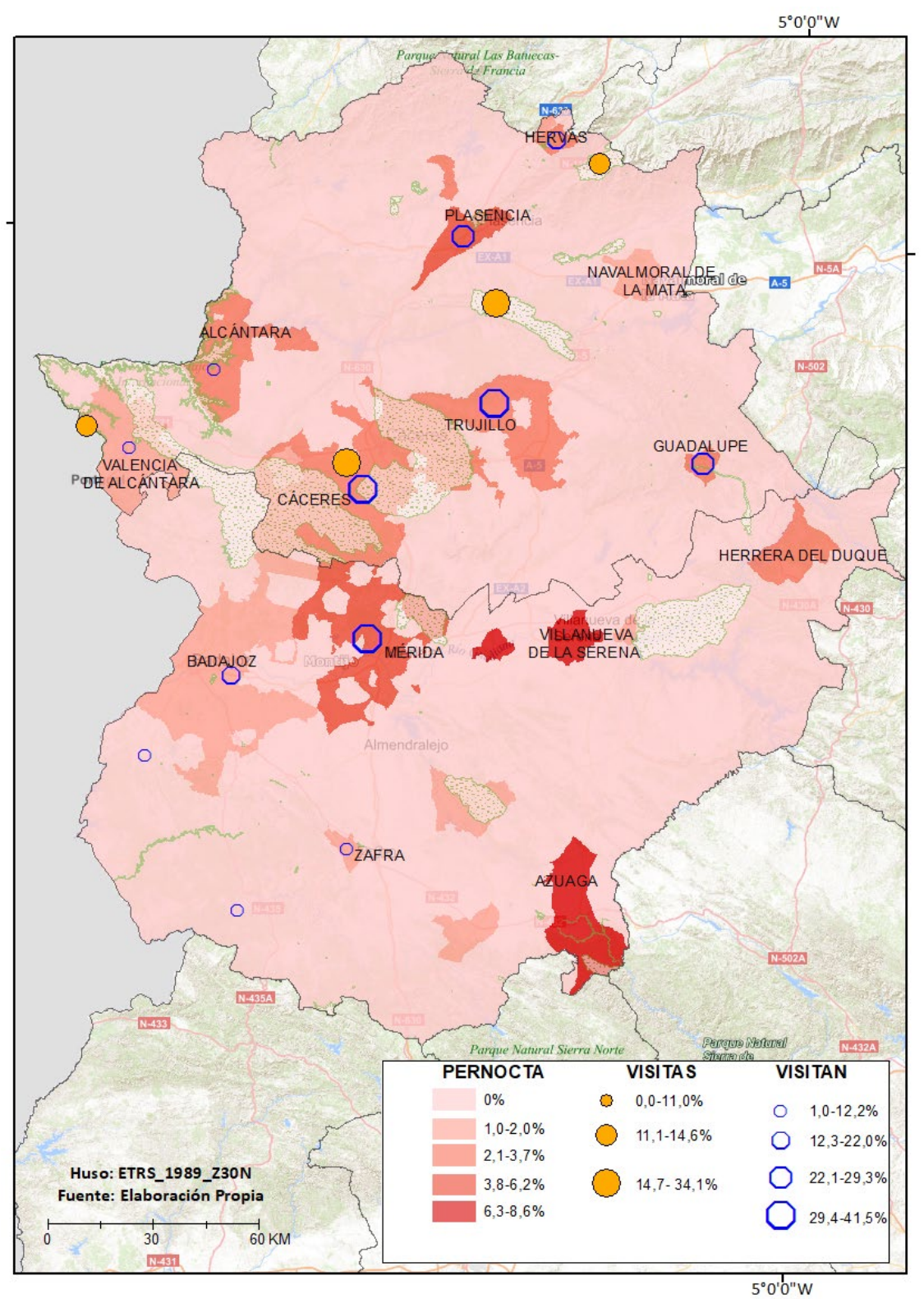

\subsection{Percepción sobre el destino del turista cinegético}

La percepción final del turista sobre un destino concreto es fundamental en el proceso de elección de futuros destinos turísticos (García et al., 2007). Por ello, se analiza la puntuación que este tipo de turistas otorga a numerosos aspectos relacionados con la disponibilidad de oferta o las facilidades de llegada a un destino, entre otras variables, siguiendo una escala de puntuación del 0 al 10. En un primer análisis se observa, en líneas generales, unos resultados 
altamente positivos teniendo en cuenta que el promedio de cada una de las variables analizadas lleva a que la valoración media del destino sea de notable alto $(8,41)$. Ya adentrándose en cada una de estas variables, se palpa una percepción bastante buena en la disponibilidad de servicios tales como alojamiento, restauración, empresas de actividades turísticas o servicios de información, las cuales reciben una puntuación promedio por encima del 8 . En segundo lugar, llama la atención la escasez de respuestas obtenidas en el caso de la accesibilidad a minusválidos (29,3\%), que puede verse motivada a las limitaciones que presenta la caza para este sector de la población. Teniendo en cuenta la valoración promedio de esta variable se observa la tarea pendiente que presenta la región extremeña en fomentar la accesibilidad a minusválidos, ya que recibe la menor puntuación entre todas las variables. En la misma línea se muestra la puntuación promedia obtenida en el caso de la señalización turística ligada de forma intrínseca a la facilidad para llegar y desplazarse que, a su vez, recibe una valoración de 8. A modo de conclusión, se puede estimar que Extremadura manifiesta una buena situación en lo que respecta a la disponibilidad de servicios, pero que, sin embargo, tiene distintas carencias en la accesibilidad a minusválidos, así como en la señalización turística que lleva a que la facilidad de llegada y desplazamiento al destino se encuentren entre las variables que perciben una menor puntuación.

Tabla 9. Valoración disponibilidad servicios

\begin{tabular}{|l|c|c|c|c|c|c|c|}
\hline & Alojamiento & Restauración & $\begin{array}{c}\text { Empresas } \\
\text { Actividades } \\
\text { Turísticas }\end{array}$ & $\begin{array}{c}\text { Accesibilidad } \\
\text { Minusválidos }\end{array}$ & $\begin{array}{c}\text { Servicios } \\
\text { Información } \\
\text { Turística }\end{array}$ & Señalización & $\begin{array}{c}\text { Facilidad } \\
\text { para Ilegar }\end{array}$ \\
\hline $\mathbf{0}$ & $0,0 \%$ & $0,0 \%$ & $0,0 \%$ & $1,2 \%$ & $0,0 \%$ & $1,2 \%$ & $0,0 \%$ \\
\hline $\mathbf{3}$ & $0,0 \%$ & $2,4 \%$ & $0,0 \%$ & $0,0 \%$ & $1,2 \%$ & $1,2 \%$ & $0,0 \%$ \\
\hline $\mathbf{4}$ & $0,0 \%$ & $0,0 \%$ & $2,5 \%$ & $1,2 \%$ & $0,0 \%$ & $2,4 \%$ & $0,0 \%$ \\
\hline $\mathbf{5}$ & $2,5 \%$ & $1,2 \%$ & $2,4 \%$ & $6,1 \%$ & $1,2 \%$ & $3,7 \%$ & $8,5 \%$ \\
\hline $\mathbf{6}$ & $2,4 \%$ & $1,2 \%$ & $4,9 \%$ & $11,0 \%$ & $3,2 \%$ & $7,3 \%$ & $6,1 \%$ \\
\hline $\mathbf{7}$ & $11,0 \%$ & $8,5 \%$ & $8,5 \%$ & $7,3 \%$ & $4,9 \%$ & $9,8 \%$ & $14,6 \%$ \\
\hline $\mathbf{8}$ & $32,9 \%$ & $31,7 \%$ & $25,6 \%$ & $18,3 \%$ & $24,3 \%$ & $25,6 \%$ & $23,2 \%$ \\
\hline $\mathbf{9}$ & $12,2 \%$ & $17,1 \%$ & $12,2 \%$ & $6,1 \%$ & $22,8 \%$ & $12,2 \%$ & $11,0 \%$ \\
\hline $\mathbf{1 0}$ & $20,7 \%$ & $23,2 \%$ & $18,3 \%$ & $19,5 \%$ & $32,9 \%$ & $20,7 \%$ & $23,2 \%$ \\
\hline NS/NC & $18,3 \%$ & $14,7 \%$ & $25,6 \%$ & $29,3 \%$ & $9,5 \%$ & $15,9 \%$ & $13,4 \%$ \\
\hline Media & $\mathbf{8 , 3 7}$ & $\mathbf{8 , 4 3}$ & $\mathbf{8 , 1 8}$ & $\mathbf{7 , 7 6}$ & $\mathbf{8 , 8}$ & $\mathbf{7 , 8}$ & $\mathbf{8 , 0}$ \\
\hline
\end{tabular}

Fuente: Elaboración Propia

El turista cinegético muestra un gran interés por el patrimonio cultural y natural generando numerosos desplazamientos por toda la región extremeña. Por ello, la Tabla 10 muestra un análisis específico sobre la percepción de este tipo de turistas en la conservación del patrimonio cultural y natural, medida en una escala que va del 0 al 10. En líneas generales el turista cinegético muestra una percepción positiva sobre la conservación del patrimonio cultural y natural en la región extremeña, dando lugar a que el promedio de puntuación sea de notable alto $(8,53)$ superando la media global de percepción del destino. 
Tabla 10. Conservación del patrimonio cultural y natural

\begin{tabular}{|l|c|c|c|c|c|c|c|c|}
\hline & $\mathbf{5}$ & $\mathbf{6}$ & $\mathbf{7}$ & $\mathbf{8}$ & $\mathbf{9}$ & $\mathbf{1 0}$ & NS/NC & PROMEDIO \\
\hline Patrimonio Cultural & $1,2 \%$ & $2,4 \%$ & $12,2 \%$ & $28,0 \%$ & $15,9 \%$ & $29,3 \%$ & $11,0 \%$ & $\mathbf{8 , 6}$ \\
\hline Patrimonio Natural & $1,2 \%$ & $3,7 \%$ & $14,6 \%$ & $28,0 \%$ & $14,6 \%$ & $25,6 \%$ & $12,3 \%$ & $\mathbf{8 , 4 6}$ \\
\hline
\end{tabular}

Fuente: Elaboración Propia

\section{DISCUSIÓN}

Algunos de los resultados obtenidos resultan llamativos. Entre ellos figura el elevado número de mujeres que han respondido la encuesta, circunstancia que pone de manifiesto que no existe una correlación entre este dato y la realidad del sector, ya que la caza es una práctica muy masculinizada, tal y como demuestran las estadísticas oficiales. Esta circunstancia se repite en otros lugares como en Córdoba, donde, a pesar de que esta cifra no se muestra de manera tan acusada, el porcentaje de mujeres que se desplaza con motivo de la práctica cinegética asciende a un considerable 17,6\% (Nogueras, Caridad y Gálvez, 2017). Entre las razones que pueden estar tras la elevada presencia de mujeres se encuentra el carácter social del cazador (Pinet, 1995), motivo por el que suele viajar acompañado, fundamentalmente en pareja, según lo descrito en este trabajo (36,6\%).

Por otro lado, se ha confirmado que el turismo cinegético puede representar una oportunidad para el mantenimiento o, incluso, desarrollo del medio rural, en línea con lo expresado en otros trabajos (Guajardo y Martínez, 2004; Danzberger, 2009; Yasuda, 2011; Pérez et al., 2015; Mbaiwa, 2018) teniendo en cuenta, además, que se trata de una actividad que está experimentado un significativo auge en las últimas décadas a nivel nacional e internacional (Rengifo, 2008). En Extremadura el sector cinegético generó un montante económico que, en la temporada 2016/17, superó los 385 millones de euros (Gallardo et al., 2018). Estos datos hay que relacionarlos, asimismo, con un contexto en el que la región debe abordar un gran reto a corto plazo, como consecuencia de la elevada tasa de desempleo, cuya cifra en 2018 se situaba en el $23,1 \%$ (EPA, 2018), junto a un elevado índice de envejecimiento $(137,46)$, una baja tasa de natalidad $\left(7,92 \%_{0}\right)$, así como una tendencia al decrecimiento de la población, fenómeno que se presenta de forma más acusada en los municipios con menos de 5000 habitantes (INE, 2019). Este panorama obliga a analizar e impulsar de forma permanente todas las actividades que aprovechan los recursos endógenos de forma sostenible, siendo la caza una de ellas. En este sentido, hay que tener en cuenta el enorme potencial de Extremadura como destino de caza, teniendo en cuenta unas condiciones paisajísticas, culturales, sociales y ambientales que permiten la existencia de multitud de especies cinegéticas muy demandadas en la actualidad (Terrón, 1975), de manera que numerosos cazadores nacionales pueden decidir desplazarse a la región para pasar unas jornadas de caza. A pesar de ello, no se entiende muy bien el motivo por el que son tan escasas las estadísticas oficiales que contabilicen los flujos generados por esta modalidad turística de carácter específico. $Y$ de esta reflexión se deriva un interrogante:

¿Qué limita a la administración pública a realizar un análisis sobre el flujo de turistas cinegéticos que eligen la región extremeña como destino para el ejercicio de la caza?

Ante esta falta de iniciativa, parece oportuno abordar esta cuestión en futuras líneas de investigación. 


\section{CONCLUSIONES}

Tras el análisis efectuado durante toda la investigación se puede realizar una aproximación a las características que presenta el turista cinegético en Extremadura.

En primer lugar, se caracteriza por la homogeneidad de género prevaleciendo el grupo etario de 46 y 55 años tal y como sucede, respecto a este último dato, en la provincia de Córdoba (Nogueras, Caridad y Gálvez, 2017). Complementariamente se ha detectado una escasa presencia de cazadores de más de 65 años, concentrando únicamente al 2,4\% de la muestra a pesar de que este grupo etario se beneficia de la exención del pago de la licencia de caza (Decreto 91/2012). Aunque no se dispone de datos sobre el número de licencias expedidas a cazadores mayores de 65 años en Extremadura, el dato obtenido en este trabajo concuerda con las cifras ofrecidas en una encuesta realizada por la Federación Extremeña de Caza (2018) donde se cifra en un $2,4 \%$ los cazadores que superan esa edad.

En cuanto a la procedencia de los encuestados, se aprecia que predominan los residentes nacionales, aunque el turista internacional tiene una gran representatividad ( $17 \%$ de los encuestados), debido al auge que ha experimentado el turismo cinegético en las últimas décadas (Rengifo, 2008). En un análisis más detallado de la muestra del turista nacional se observan dos puntos claves: la importancia que tiene la cercanía, ya que la mayor parte de ellos proceden de provincias limítrofes, o muy bien comunicadas, como Madrid o Sevilla; y el importante peso que tienen los cazadores residentes en Extremadura.

En segundo lugar, el viaje realizado por el turista cinegético en Extremadura no se limita al ejercicio de las artes venatorias, sino que incluye cuantiosas actividades entre las que cabe destacar las visitas culturales, el disfrute de la gastronomía de la zona, así como el turismo rural. Debido al carácter social que presentan los cazadores, es lógico que el viaje se realice acompañado, fundamentalmente en pareja, familia o con amigos. Estos hechos constatan las posibilidades que presenta el turismo cinegético como complemento a otras modalidades turísticas, así como la capacidad de atracción del cazador, ya que puede desplazarse junto a personas ajenas al mundo de la caza.

En líneas generales, el cazador organiza el viaje por internet o siguiendo las recomendaciones de familiares y amigos, teniendo una escasa repercusión otro tipo de vías más tradicionales como sería el caso de las agencias de viajes. Con respecto a la duración de éste, se ve limitado a los días hábiles de caza generalistas, coincidentes con el fin de semana y puentes, así como al jueves en el caso de algunas modalidades específicas. En estas pernoctaciones, el turista cinegético se inclina por alojamientos con una categoría entre 1 y 3 estrellas, la casa del familiar o amigo, así como el alojamiento rural. Esta situación conduce a que el gasto medio diario en el hospedaje sea reducido, debido a la incidencia del alojamiento gratuito en casa de familiares o amigos. En cambio, el gasto promedio diario es elevado en el caso de la alimentación y otras compras, debido al notable interés por la gastronomía que muestra este turista.

En tercer lugar, se ha podido observar la gran movilidad que caracteriza al turista cinegético en Extremadura, que se desplaza por todo el territorio, motivado precisamente por la presencia de un rico patrimonio cultural y natural, destacando como principales localidades visitadas Cáceres, Trujillo y Mérida. 
Por último, la valoración general sobre el destino extremeño es ciertamente positiva en todos los aspectos analizados (hospitalidad, disponibilidad, de servicios, etc.) que llevan a que el promedio de puntuación global del destino se sitúe en 8,41 .

Los resultados alcanzados en esta investigación responden ampliamente a los objetivos planteados al inicio, ya que se caracteriza el perfil del turista cinegético en la región extremeña a través de datos sociodemográficos, principales características que presenta la movilidad, y su percepción sobre la calidad de Extremadura como destino de turismo cinegético.

Finalmente, ante la escasa presencia de trabajos que aborden el perfil de este tipo de turistas, este trabajo supone un avance en el conocimiento, del que se pueden derivar actuaciones fundamentales para el diseño de una oferta adecuada, así como para potenciar este sector que aporta cuantiosos beneficios de distinta índole al medio rural en Extremadura.

Ante este panorama, existe un largo camino por recorrer en el turismo cinegético extremeño, ya que son escasas las estadísticas que permiten conocer la situación real de este sector, provocando un profundo vacío en relación con las posibles carencias y necesidades que pueden afectar a este tipo de turismo en Extremadura.

Como futuras líneas de investigación que traten de paliar estas deficiencias se plantean las siguientes:

- Un análisis más detallado de los movimientos que realiza el turista cinegético en Extremadura.

- Abordar con una mayor profundidad el interés del turista cinegético por el desarrollo de actividades complementarias a la práctica venatoria.

\section{Agradecimientos}

Esta publicación se encuadra dentro de las investigaciones llevadas a cabo durante la ejecución del proyecto "Diseño y elaboración de productos estratégicos diferenciados para la potenciación del turismo rural en Extremadura. De la detección de problemas a la propuesta de soluciones basadas en criterios geoestadísticos", cuya clave es IB 16040, y se encuentra financiado por la Consejería de Economía e Infraestructuras de la Junta de Extremadura y por el Fondo Europeo de Desarrollo Regional (FEDER).

\section{REFERENCIAS BIBLIOGRÁFICAS}

Adrover, A. B.; Sebastián, J. B. y Gelabert, M. G. (2016): Caracterización del perfil social y territorial del cazador mallorquín. In Treinta años de Política Agraria Común en España: Agricultura y multifuncionalidad en el contexto de la nueva ruralidad, 496-511. Recuperado de $:$ https://dialnet.unirioja.es/servlet/articulo?codigo=6274404

Adrover, A.B.; Grimalt, M. y Binimelis, J. (2017): Planificación y ordenación territorial de la caza. Hacia una comercialización cinegética en Mallorca. Cuadernos geográficos, 57 (2), 138-161. http://dx.doi.org/10.30827/cuadgeo.v57i2.5847 
Adrover, A. B.; Seguí, B. y Rengifo, J.I. (2017): La caza de la cabra salvaje mallorquina en el contexto del turismo cinegético, Ería (2), 233-252. https://doi.org/10.17811/ er.2.2017.233-252

Adrover, A. B.; Grimalt, M. y Binimelis, J. (2017): Análisis bibliométrico de los estudios geográficos de la caza en España (1978-2015), Boletín de la Asociación de Geógrafos Españoles, N. $o$ 74, 301-332. http://dx.doi.org/10.21138/bage.2456

Alvarado, E. (1983): Los espacios rurales y el ocio: los cotos de caza. Coloquio de Geógrafos españoles. Comunicaciones (págs. 149-155).

Alvarado, E. (1991): La actividad cinegética en Extremadura. Agricultura y sociedad, 58, pp. 215-240. Recuperado de: https://www.mapa.gob.es/ministerio/pags/biblioteca/revistas/pdf ays/a058 08.pdf

Álvarez, P. (2007): El turismo cinegético como recurso económico de la provincia de Cáceres. Cáceres. Cámara de comercio.

Andueza, A.; Lambarri, M.; Urda, V.; Prieto, I.; Villanueva, L.; Sánchez-García, C. (2018a): Evaluación del impacto económico y social de la caza en España. Ciudad Real: Fundación Artemisan.

Andueza, A.; Lambarri, M.; Urda, V.; Prieto, I.; Villanueva, L.; Sánchez-García, C. (2018b): Evaluación del impacto económico y social de la caza en España. Ciudad Real: Fundación Artemisan.

Arizón, M.; Garcés, S. y Sangrá, M. (2012): Perfil del turista de festivales: el caso del Festival Internacional de las Culturas Pirineos Sur. Cuadernos de turismo, (30), 63-90. Recuperado de : https://revistas.um.es/turismo/article/view/160451.

Aryal, A.; Dhakal, M.; Panthi, S.; Yadav, B.; Shrestha, L.; Bencini, R.; Raubenheimer, D. (2015): Is trophy hunting of bharal (blue sheep) and Himalayan tahr contributing to their conservation in Nepal?. Hystrix-Italian Journal of Mammalogy,26 (2), 85-88. Recuperado de : https://eprints.usq.edu.au/28181/

Baltar, E. (2002): La montería de Azuaga se dispara. El Periódico. Extremadura. Recuperado de: https://www.elperiodicoextremadura.com/noticias/extremadura/monteria-azuaga-dispara_28130.html

Bardají, M. (1987): La caza en las dehesas extremeñas. Comunicaciones con motivo del I Congreso Internacional de la Caza en Extremadura, 225-231. Diputación de Cáceres.

Bauer, J. y Giles, J. (2002): Recreational hunting: an International perspective. CRC for sustainable tourism.

Bielsa, J. (1987): Caza mayor como alternativa de desarrollo en zonas deprimidas de Extremadura. Comunicaciones con motivo del I Congreso Internacional de la Caza en Extremadura, 167-185. Diputación de Cáceres.

Borrel, M. (1964): Caza y turismo. Estudios Turísticos, №. 2, 57-73. Recuperado de : http:// estadisticas.tourspain.es/img-iet/Revistas/RET-2-1964-pag57-76-41983.pdf

Bredis, K. y Coca, J.L. (2010): Turismo cinegético en Extremadura (trabajo fin de grado). Cáceres. Universidad de Extremadura

Calvo, M.S. (2003): El Ingeniero de montes y el medio ambiente: el desarrollo rural y la ordenación del territorio. Revista Forestal Española (RFE), (32), 30-35.

Cassinello, J. (2013): La caza como recurso renovable y la conservación de la naturaleza. España: Consejo Superior de Investigaciones Científicas. 
Consejería de Medio Ambiente y Rural, Políticas Agrarias y Territorio. Dirección General de Medio Ambiente. (2018): Recuperado de: http://extremambiente.juntaex.es/index. php?option=com content\&view=article\&id=3657\& Itemid $=310$

Crosmary, W.; Côté, S. y Fritz, H. (2015): The assessment of the role of trophy hunting inwildlife conservation. Animal Conservation, 18 (2), 136-137. https://doi.org/10.1111/ acv.12205

Danzberger, J.B. (2009): La caza: un elemento esencial en el desarrollo rural. Mediterráneo Económico: El nuevo sistema agroalimentario en una crisis global, 15, 183-203.

Decreto 91/2012, de 5 de mayo, por el que se aprueba el reglamento por el que se regula la gestión cinegética y el ejercicio de la caza. Recuperado de: $\underline{h t t p: / / d o e . g o b e x . e s / p d f s / ~}$ doe/2012/1050o/12040101.pdf

Dirección General de Medio Ambiente. Servicio de Recursos Cinegéticos y Piscícolas Consejería de Medio Ambiente y Rural, Políticas Agrarias y Territorio Junta de Extremadura. Datos propios. 2017.

Federación Extremeña de Caza (2019). Datos Propios.

Folgado, J.A.; Hernández, J.M. y Oliveira, P.A. (2014): El perfil del turista de eventos culturales: análisis exploratorio. Cultura, desarrollo y nuevas tecnologías: VII Jornadas de investigación en turismo, 57-74.

Gallardo, M.; Gallardo, J.M; Gómez, M.; Rodero, S. (2017): Situación de la Caza en Extremarua. Informe Anual 2015-2016. Badajoz. Federación Extremeña de Caza.

García, R.C.P.; Morales, L.M. y González, Y.D. (2007): La imagen del destino y el comportamiento de compra de turista. Teoría y Praxis (3), 89-102. Recuperado de: https://dialnet.unirioja.es/servlet/articulo?codigo $=2929607$

González, Y.E.L. y Ledesma, J.D.L. (2015): El perfil del turista náutico en el destino de Cabo Verde. Revista Perspectiva Empresarial. ISSSN: 2389-8194, 2(2).

Guajardo, R. y Martínez, A. (2004): Cuantificación del impacto económico de la caza deportiva en el norte de México y perspectivas de su desarrollo. Entorno Económico, 42(250), 1-17. Recuperado de : http://eprints.uanl.mx/id/eprint/8690

Hofer, D. (2002): The lion's share of the hunt. Trophy hunting and conservation: a reviewof the legal Eurasian tourist hunting market and trophy trade under CITES. TRAFFIC Europe, Bruselas

INE (2017): Cifras oficiales de población de los municipios españoles: Revisión del Padrón Municipal. Madrid: Instituto Nacional de Estadística. Recuperado de: $\underline{\text { https://www.ine. }}$ es/dyngs/INEbase/es/categoria.htm?c=Estadistica P\&cid=1254734710990

INE. (2017): Encuesta de ocupación hotelera. Madrid: Instituto Nacional de Estadística. Recuperado de: http://www.ine.es/iaxiT3/Tabla.htm?t=2074\&L=0

INE. (2018): Encuesta de Población Activa. Tasa de Paro. Madrid: Instituto Nacional de Estadística. Recuperado de https://www.ine.es/dynt3/inebase/es/index. htm?padre $=990 \&$ capsel $=994$

INE. (2018): Encuesta de turismo de residentes. Madrid: Instituto Nacional de Estadística. Recuperado de https://www.ine.es/ss/Satellite?L=0\&c=INEPublicacion C\&cid= $1259948665643 \& \mathrm{p}=1254735110606 \&$ pagename $=$ Productos YServicios\%2FPYSLayout\&tittema=Servicios 
Junta de Extremadura (2015): Plan General de Caza. Recuperado de http://extremambiente. juntaex.es/files/Informacion\%20Publica/2015/octbre/Anteproyecto\%20PGCEx\%20 -\%20optimizado.pdf

Junta de Extremadura (2017): Plan turístico de Extremadura 2017-2020. Recuperado de http://www.turismoextremadura.com/viajar/shared/documentacion/publicaciones/ PlanTuristicoExtremadura2017 2020.pdf

Komppula R. y Gartner W. (2013): Hunting as a travel experience: An auto-ethnographic of hunting tourism in Finland and the USA. Tourism Management, 35, 168-180. https:// doi.org/10.1016/i.tourman.2012.06.014

Krüger, S.; Barrat, E. y Van der Merwe P. (2015): Determining the impact of hunting trips on the hunters quality of life. African Journal of Hospitality, Tourism and leisure, 4 (2), 1-17. Recuperado de: http://hdl.handle.net/10394/20427

Leader-Williams, N.; Kayera, J. y Overtoil (1996): Tourist hunting in Tanzania. IUCN, Cambridge. Leco, F. (1997): Potencialidades turísticas de las dehesas extremeñas: la actividad cinegética. En M. Valenzuela, Los turismos de interior: el retorno a la tradición viajera. Madrid, 161-168.

Lewis, D. y Alpert, P. (1997): Trophy Hunting and Wildlife Conservation in Zambia: Caza Deportiva y Conservación de la Vida Silvestre en Zambia. Conservation Biology, 11(1), 59-68. https://doi.org/10.1046/i.1523-1739.1997.94389.x

Ley 14/2010, de 9 de diciembre, de Caza en Extremadura. Recuperado de: http://doe.gobex. es/pdfs/doe/2010/2390o/10010016.pdf

Lindsey, P.A.; Roulet P.A. y Romañach S.S. (2007): Economic and conservation significance of the trophy hunting industry in sub-saharian Africa. Biological Conservation, 134, 455469. https://doi.org/10.1016/i.biocon.2006.09.005

Mackenzie, J. (2018): Hunting Africa. British sport, African knowledge and the nature of empire. Agricultura history review, 66 (2), 299-301.

Mbaiwa, J. (2018): Effects of the safari hunting tourism ban on rural livelihoods and wildlife conservation in Northern Botswana. South African Geographical Journal, 100 (1), 41-61. https://doi.org/10.1080/03736245.2017.1299639

Mbaiwa, J.E. (2004): The Socio-Economic benefits and challenges of a Community-Based Safari Hunting Tourism in the Okavango Delta, Botswana. The Journal of tourism studies, Vol. 15, no 2, 38-50. Recuperado de: https://search.informit.com.au/ documentSummary;dn=200501357; res=IELAPA;type=pdf

McGuigan, L. (2017): The hunting industry: Exploring the marriage of consumerism, sport hunting, and commercial entertainment. Journal of consumer culture,17 (3), 910-930. https://doi.org/10.1177/1469540516634415

Metra Seis (1985). Turismo Cinegético en España. Madrid: Secretaría General de Turismo. Ministerio de transportes, turismo y comunicaciones.

Ministerio de Agricultura y Pesca, Alimentación y Medio Ambiente (2007): Estrategia Española de Desarrollo Sostenible. Madrid. Recuperada de : https://www.mapama.gob.es/es/ ministerio/planes-estrategias/estrategia-espanola-desarrollo-sostenible/

Ministerio de Interior, U. D.; Service, U. F.; Commerce, U. D. (2016). 2016 National Survey of Fishing, Hunting, and Wildlife-Associated Recreation. Estados Unidos. Recuperado de: https://wsfrprograms.fws.gov/subpages/nationalsurvey/nat survey2016.pdf 
Mulero, A. (1991): Turismo y caza en España. Estado de la cuestión. Agricultura y sociedad (58), 147-171. Madrid. Recuperado de : https://helvia.uco.es/bitstream/ handle/10396/5618/a058 05.pdf?sequence=1

Nogueras, J. D. R.; Caridad, J. M. y Gálvez, J. C. P. (2017): El perfil del turista cinegético: un estudio de caso para Córdoba (España). International journal of scientific management and tourism, 3 (4), 187-203. Recuperado de : https://dialnet.unirioja.es/servlet/ articulo?codigo $=6182529$

Ochieng, A.; Visseren-Hamakers, I.; y Van der Duim, R. (2018): The battle over the benefits: analysing two sport hunting policy arrangements in Uganda. ORYX, 359-368.

OMT (2018): Panorama OMT del turismo internacional. Edición 2018. Recuperado de: https:// www.e-unwto.org/doi/book/10.18111/9789284419876.

Orden de 7 de junio de 2016 General de Vedas de Caza para la temporada 2016/2017, de la Comunidad Autónoma de Extremadura. Recuperado de : http://doe.gobex.es/pdfs/ doe/2016/1120o/16050163.pdf

Pérez, J. L.; Casado, P. P.; Del Río, M. D.; García, J. Á. (2015): La diversificación económica sostenible del medio rural a través del turismo cinegético. CULTUR: Revista de Cultura e Turismo, 9(3), 44-63. Recuperado de: https://dialnet.unirioja.es/servlet/ articulo?codigo $=5309810$

Petroman, I.; Petroman, C.; y Marin D. (2015): Place of Hunting Tourism in the Structure of Modern Tourism Types. Animal Science and Biotechnologies, 48 (2), 199-202. Recuperado de: http://www.spasb.ro/index.php/spasb/article/view/1925/pdf

Pinet, J.M. (1995): The Hunters in Europe. Recuperado de: https://www.kora.ch/malme/05 library/5 1 publications/P and Q/Pinet 1995 The hunters in Europe.pdf

Propuesta de ley por la que se modifican la ley 14/2010, de 9 de diciembre de caza en Extremadura y la ley 18/2001, de 14 de diciembre, sobre tasas y precios públicos de la comunidad autónoma de Extremadura.

Rengifo, J. (2008). Un segmento del turismo internacional en auge: el turismo de caza. Cuadernos de turismo, 22, 187-210. Recuperado de : https://revistas.um.es/turismo/ article/view/48181

Rengifo, J.I. (2009): La oferta de caza en España en el contexto del turismo cinegético internacional: las especies de caza mayor. Ería, 78-79, 53-68.

Rengifo, J. (2010): Caza y turismo cinegético como instrumentos para la conservación de la naturaleza/Hunting and hunting tourism as tools for nature conservation. . Anales de Geografía de la Universidad Complutense, 30 (2), 163-186. Recuperado de: https:// revistas.ucm.es/index.php/AGUC/article/view/AGUC1010220163A

Rengifo, J. I. (2010): Usos turísticos de los recursos cinegéticos en la Extremadura del siglo XXI. En Actas del XV Coloquio de Geografía Rural. Territorio, paisaje y patrimonio rural (Leco, F. coord.). Cáceres, Universidad de Extremadura.

Rengifo, J. I. (2011): Una visión general del turismo cinegético. Papeles de Economía Española, 128, 228-236.

Rengifo, J.I. (2012): Evaluación de la actividad cinegética en Extremadura en los albores del siglo XXI. Retos a corto y medio plazo. Estudios Geográficos 73 (272), 189-214. https:// doi.org/10.3989/estgeogr.201207 
Rengifo, J.I. (2013): Una visión general sobre el turismo en regiones de la Raya Ibérica: referencias a Extremadura. En Turismo de Frontera I (Campesino, A. dir.). Vigo, RIET.

Rengifo, J.I.; Pérez, A. y Leco, F. (2013): La calidad como mecanismo de diferenciación del turismo cinegético. Turismo e Innovación. VI Jornadas de Investigación en turismo (págs. 451-467. Universidad de Sevilla. Facultad de Turismo y Finanzas.

Rengifo, J.I. y Sánchez, J.M. (2016): Caza y Espacios Naturales Protegidos en Extremadura. Investigaciones Geográficas (65), 57-73. https://doi.org/10.14198/INGEO2016.65.04

Resolución de 12 de febrero de 2019, de la Consejera, por la que se aprueba la oferta pública de caza, se elevan a definitivos los listados de admitidos al sorteo y se determina la fecha de celebración del mismo. Recuperado de: http://doe.gobex.es/pdfs/ doe/2019/410o/19060462.pdf

Saayman, M.; Van der Merwe, P. y Saayman, A. (2018): The economic impact of trophy hunting in the south African wildlife industry. Global ecology and conservation, 16, 1-9. https:// doi.org/10.1016/i.gecco.2018.e00510

Samuelson, E. y Stage, J. (2007): The size and distribution of the economic impacts of Namibian hunting tourism. South African Journal of Wildlife Research 37(1) 41-52. https://doi. org/10.3957/0379-4369-37.1.41

Sánchez, J.M. y Rengifo, J.I. (2016): Los Espacios Naturales Protegidos y su capacidad de atracción turística: referencias al Parque Nacional de Monfragüe (Extremadura-España). 24 ${ }^{\circ}$ Congreso APDR, julio de 2017, Covilhã, Portugal, 1196-1271.

Sastre, A. y Payeras, M. (2004). Diferencias en el perfil del turista de la temporada alta y baja en Baleares. Universitat de Les Illes Balears.

Terrón, M. (1975): De la panorámica de la caza en Extremadura. En C. Orellana, Los libros de la caza española, 473-520. Madrid.

Torres, E. (2006): El sistema de actividades turísticas. En Torres, E. (Coord.) Estructura de mercados turísticos, 15-12. Barcelona.

Urquijo, A. (1987): Extremadura y la oferta de caza en todas sus vertientes. La caza en Extremadura. Comunicaciones con motivo del I Congreso Internacional de la Caza en Extremadura, 25-31. Diputación de Cáceres.

Willebrand, T. (2009): Promoting hunting tourism in north Sweden: opinions of local hunters. European Journal of Wildlife research, (55), 209-216. Recuperado de : https://link. springer.com/article/10.1007/s10344-008-0235-2

Yasuda, A. (2011): The Impacts of Sport Hunting on the Livelihoods of Local People: A Case Study of Benoue National Park, Cameroon. Society and Natural Resources, 860-869. https://doi.org/10.1080/08941920.2010.486394 